\title{
Geo-helminthes Associated with Geophagic Pupils in Selected Primary Schools in Oyi, Anambra State
}

\author{
Okereke J. N. ${ }^{1,}$ ", Obasi K. O. ${ }^{2}$, Nwadike P. O. ${ }^{3}$, Ezeji E. U. ${ }^{1}$, Udebuani A. C. ${ }^{1}$ \\ ${ }^{1}$ Department of Biotechnology, Federal University of Technology, Owerri, Nigeria \\ ${ }^{2}$ Department of Biological Science, Federal University of Technology, Owerri, Nigeria \\ ${ }^{3} \mathrm{KNCV}$ Nigeria / Challenge TB Project, Abuja, Nigeria
}

\section{Email address:}

kayboy2013@live.com (Obasi K. O.), petrousbone@yahoo.com (Nwadike P. O.), ucheezeji@yahoo.com (Ezeji E. U.), chibufo@yahoo.com (Udebuani A. C.), chinwendubueze1@yahoo.com (Okereke J. N.)

\section{To cite this article:}

Okereke J. N., Obasi K. O., Nwadike P. O., Ezeji E. U., Udebuani A. C.. Geo-helminthes Associated with Geophagic Pupils in Selected Primary Schools in Oyi, Anambra State. Science Journal of Public Health. Special Issue: Who Is Afraid of the Microbes.

Vol. 3, No. 5-1, 2015, pp. 45-50. doi: 10.11648/j.sjph.s.2015030501.19

\begin{abstract}
Identification of geo-helminthes associated with geophagy as well as risk factors predisposing to such infestations among primary school pupils were carried out. Ethical permissions were obtained from headteachers of schools and pupils to collect stool samples of 200 volunteer pupils, aged 5-13years (106 males and 94 females) from rural and urban primary schools in Oyi Local Government Area of Anambra State, Nigeria. Stool samples were examined microscopically using wet mount (normal saline and iodine) technique. Data collected via questionnaires were analyzed to assess the relationship between geophagia, regular ingestion of soil and soil-transmitted parasites. Three intestinal parasites: Ascaris lumbricoides (A.lumbricoides), Ancylostoma duodenale (A. duodenale) and Trichuris trichiura (T. trichiura) were commonly observed. A total of 178 pupils $(89 \%)$ found to be infected with one or more of these worms. A.lumbricoides had the highest prevalence of $52.8 \%$, while A.duodenale and T.trichiura had $32.58 \%$ and $14.61 \%$ respectively in all five villages in the Local Government Area. Infection rates and geophagic habits were established to be highest in children between the ages of 5 and 7 years $(p>0.05)$. Location and sex were observed to be insignificant factors in the distribution of these parasites $(p>0.05)$. Geophagy and any other form of contact with the topsoil and children orally should therefore be noted as an important risk factor for orally acquired parasitic infections among children. Education on geophagy prevention should be an integral component of all soil-transmitted parasite control programs.
\end{abstract}

Keywords: Geophagy, Intestinal Helminthes, Pupils, Anambra State

\section{Introduction}

Throughout history, the practice of eating earth or earthylike substances such as clays, chalks and starches have been practiced among all religions, races and people of all ages; both male and female. Geophagy can be described as a form of pica in which non-food substances are ingested by living things. Humans and animals across all continents practice geophagy in a variety of forms making it one of the most common types of pica [1].

In animals, geophagy is considered to be an adaptive behavior that is documented among numerous animal groups including primate species [2]. Populations that mostly engage in geophagy live in rural areas; practice a traditional culture, and have little or no access to healthcare facilities.
Within these high risk communities, geophagy is common among young children and pregnant women who have a family history of pica passed along to them and for this reason, it is said to be a tradition passed on through generations [3]. There has been an established link between geo-helminthic infestation and geophagic practice. However, in terms of vulnerability to geophagic practices, children are the most infected. This could be due to their constant hand to mouth activity such as using bare hands to eat without washing especially after a play-ground activity, picking and ingestion of fallen fruits without washing, playing with earth during traditional recreation and lots more. This explains the need for periodic de-worming and laboratory tests [4]. Intestinal parasites that can be contacted through geophagic activities are known as soil-transmitted helminthes (STHs). 
Soil-transmitted helminthes can cause contamination during ingestion or unnecessary skin contact with infected soil. These STHs may include Ascaris lumbricoides, Trichuris trichiura and Ancylostoma duodenale. A large part of the world's population is infected with one or more of these soil-transmitted helminthes. Recent statistics have shown that more than 1.5 billion or $24 \%$ of the world's population are infected with STHs. These infections are widely prevalent and distributed in tropical and sub-tropical areas with greatest numbers occurring in Sub-Saharan Africa, the Americas, China and Asia. Over 270 million pre-school children and over 600 million children live in areas where the parasites are intensively transmitted [5].

Adults and adolescents however are not left out; they can consume heavy metals, parasitic eggs, or become addictive to geophagic materials, sometimes, regarding such as a food supplement. Reasons for practice abound which include among others its ability to eliminate nausea and morning sickness, for sexual purposes, replenishing of supposed lost minerals, beautification of skins and detoxification of the alimentary canal [3]. However, it also comes with adverse health effects such as the accumulation of heavy metals in the system, hypocalcaemia (loss or unavailability of potassium in the system) and mortality in some areas [6].

The theories developed to explain the etiology of geophagy may be either functional and/or cultural. Functional theory focuses on the physiological drivers, whereas the cultural focuses on the sociological drivers and cultural evolution of earth eating traditions.

The first and simplest functional explanation is that people consume soil or clay because they have insufficient food. Incidents of geophagy have certainly been documented in times of famine and insecurity [7]. Another functional theory proposes that humans eat earth in response to receiving insufficient nutrients [8]. This crucial link between geophagy and micronutrient deficiencies is supported by the observation that individuals with heightened nutritional needs; children and pregnant women are the primary geophagists [6]. Some studies have also proposed that it is a pre-existing nutrient deficiency from a lacking diet that creates the physiological desire to engage in geophagy [9]. Others however suggest that the ingestion of materials such as clay and soil binds and blocks the absorption of minerals such as iron and zinc into the blood stream, thus creating the observed deficiency [10]. Soils with high ion-e xchange capacity (largely negative substances) can bind and absorb nutrients (cations) into their surface, decreasing their availability for absorption into the bloods tream [4].

Another hypothesis incorporates two viewpoints and suggests that geophagy is both the cause and result of deficiencies. Geophagy may be initially driven by a deficit in the diet but then, also leads to the binding of nutrients in the gut, which then exacerbates the deficiencies and reinforces the behavior [11]. Although many studie have shown a correlation between mineral deficiencies and geophagy, it is difficult to determine the net effect of the ingestion of different soil types on nutrient availability in the gut. It is also on record that clay consumption is common during pregnancy, and that geophagy alleviates gastro-intestinal distress [6]. It is postulated that clay and soil can absorb pathogens and toxins preventing their entry into the blood stream or intestinal endothelium [12]. Geophagy is also perceived as an adaptive behavior to enhance immune system function. The ingestion of soil may help prevent asthma and aid in the development of a healthy immune system [3].

Eating earth is often associated with rituals, traditions and religion. In many parts of Central America, geophagy is clearly, deeply in grained in religious practice [13]. It is important to note that the cultural link of geophagy is not inherent worldwide. In many parts of the world, the practice is highly stigmatized and geophagists carry out the behavior in solitude [8].

The best studied potential consequence of geophagy is the risk of ingesting soil-borne infectious parasites, such as hookworm, roundworm, whipworm etc. These parasites are associated with malnutrition and fetal nervous damage in children. Another proposed consequence of geophagy is Lead poisoning with case studies suggesting the concurrence of Lead poisoning and geophagy [10]. Lead poisoning/exposure can lead to maternal and fetal kidney damage, encephalopathy, and impaired cognitive function [6]. Other documented health impacts of geophagy include constipation, bowel obstruction and hypokalemia, poisoning due to other toxins present in the environment as a possible exacerbation of malnutrition. Additionally, some studies have hypothesized possible associations of maternal geophagic behavior with negative birth outcomes such as low birth weight, neural tube defects, small head circumference, premature birth and elevated prenatal mortality, likely due to heavy metal toxicity and maternal nutrition [10]. Studies comparing the micronutritional value of geophagic materials and pharmaceutical supplements for pregnancy show surprising comparability for several important nutrients, including calcium, magnesium and iron [14].

Among children in Nigeria, the most common parasitic infection associated with geophagy is Ascariasis [15]. Possible geo-helminthes found in soil eaten by geophagists include Trichuris trichiura, Ascaris lumbricoides and Ancylostoma duodenale. Wide and unrestricted spread of the helminthic infection among primary school pupils has been attributed to lack of functional toilet facilities, geophagia and preference of the pupils to defecate in the bush close to school premises [16]. Most geo-helminthes ova require moisture to remain viable and when the soil ingested is recently contaminated by viable helminth eggs, the risk of infection becomes inevitable. Furthermore,immunecompromised status of some pupils can render them susceptible to a myriad of infections after exposure [17].

According to World Health Organization [5], strategies of controlling soil-transmitted helminthic infections should be carried in order to control morbidity. People at risk should be given periodic drugs (de-worming). Health and hygiene education reduces transmission and re-infection by encouraging healthy behaviors. Provision of adequate 
sanitation is also important but not always possible in resource-poor settings [5]. Drugs such as Albendazole and Mebendazole are used in treatment, which alter the production of an enzyme by the organism, thereby preventing the worms from being digested in the alimentary canal.

Diagnostic measures either by periodically sampling and further examination of stool samples or the application of adhesives which may be applied to the anus in order to search for eggs [18] are necessary to ascertain helminthic infestations in, especially vunerable populations.

\subsection{Research Aim}

The was aimed at determining/ascertaining geo-helminthic infestation of geophagic primary school pupils in Oyi, Anambra State.

\subsection{Research Hypotheses}

1. There is no relationship between geohelminthic infestation and geophagy among primary school pupils in Oyi L.G.A of Anambra State.

2. The sex of geophagic pupils does not affect parasite infestation.

3. Age group is not a significant factor in the distribution of these parasites among geophagic pupils in Oyi L.G.A of Anambra State.

\section{Methodology}

\subsection{Study Area}

The study was conducted among selected primary school pupils in Oyi Local Government Area of Anambra State, Nigeria. Oyi is located on the coordinates $5^{\circ} 15^{\prime} 0$ " North and $6^{\circ} 13^{\prime} 0$ " E of the Greenwich Meridian. It is made up of five (5) towns namely: Nkwelle Ezunaka, Awkuzu, Ogbunike, Umunya and Nteje. The soil in this area is mostly clayey in nature with a few loamy areas. Toilet facilities include water closets (owned by some public servants) and pit latrines, while others practice defecation in open places.

\subsection{Administration of Questionnaires}

Structured questionnaires were administered to the pupils through their teachers and some, through their parents/guardians. The questionnaires covered both demographic, physiological and socio-cultural variables, etc.

\subsection{Stool Sample Collection}

Certain schools were selected due to the kind of play grounds present. Volunteer pupils of different sexes were randomly selected and stool samples harvested with airtight, dry sampling bottles, labeled and stored with $10 \%$ formalin solution ( 3 parts per specimen) after collection as described by [19]. Informed consent was obtained from the headteachers of schools as well as the volunteer pupils were obtained prior to sample collection.

\subsection{Laboratory Investigations}

The laboratory investigations were done using standard protocols as described by Cheesbrough [19] as follows:

\subsubsection{Macroscopy}

Appearance of stool specimens were checked and recorded. The macroscopic parameters that were checked included: Colour of the specimen, consistency (formed, unformed or watery), presence of blood, mucus and pus for pupils with inflammation of the intestinal tract and presence of motile worms.

\subsubsection{Microscopy}

For microscopy, a drop of normal saline solution was placed on the center of a sterilized glass slide, and iodine on another with a dropping pipette. Using a wireloop, some amount of the stool specimen was collected (about $2 \mathrm{mg}$ ), dropped on the slide, and smooth preparations made. Preparations were then gently covered with the coverslip and examined systematically under the microscope with X10 and X40 objectives respectively for the presence of larva, eggs and cysts.

Observed parasites were identified accordingly based on morphological characteristics of their eggs and larva. Iodine preparations assisted in the identification of cysts especially when visibility was poor in the saline solution [19].

\section{Results}

A total of 200 stool samples were collected. Table1 shows the prevalence of geophagia among primary school children in Oyi L.G.A. Most respondents admitted that addiction to the practice was borne out of curiosity while peer influence contributed the highest percentage, $150(75 \%)$ of pupils that were geophagic.

Generally, the prevalence of geophagy among primary school pupils stood at $89 \%$. Geo-helminthic parasites observed were A.lumbricoides, T.trichuira and A.duodenale (Table2). A.lumbricoides recorded the highest prevalence of $52.8 \%$, while A.duodenale and T.trichiura were $32.58 \%$ and $14.61 \%$ respectively. Table 3 shows the distribution of these parasites according to different locations.

Table 1. Summary of Demographic data of Respondents and their Responses.

\begin{tabular}{ll}
\hline Participants & Number (\%) \\
\hline Total & $200(100)$ \\
Males & $110(55)$ \\
Females & $90(45)$ \\
Agerange of participants & \\
5-7 years & $86(43)$ \\
$8-10$ years & $50(25)$ \\
11-13 years & $64(42)$ \\
Occupational Background of parents & \\
Wage earner & $30(15)$ \\
Farming & $136(68)$ \\
Self Employed & $34(17)$ \\
Parents Educational Background & \\
Primary Education & $42(21)$ \\
Secondary Education & $136(68)$ \\
Tertiary Education & $22(11)$ \\
\end{tabular}




\begin{tabular}{ll} 
Introduction to the Practice & Number (\%) \\
Peers & $150(75)$ \\
Parents & $20(10)$ \\
Self-discovery & $30(15)$ \\
Addiction & \\
Yes & $46(23)$ \\
Sometimes & $136(68)$ \\
Never & $18(9)$ \\
Reasons for practice & \\
Taste & $58(29)$ \\
Colour & $38(19)$ \\
Size & $16(8)$ \\
Curiosity & $60(30)$ \\
Other & $28(14)$ \\
Licking of fingers & \\
Never & $26(13)$ \\
Regularly & $48(24)$ \\
Occasionally & $126(63)$ \\
Deworming & \\
Never & $112(56)$ \\
Regularly & $26(13)$ \\
Occasionally & $62(31)$ \\
Type of playground & \\
Grassy & $144(72)$ \\
Sandy & $22(11)$ \\
Indoors & $14(7)$ \\
None & $20(10)$ \\
Source of drinking water & \\
Boreholes & $38(19)$ \\
Streams/Springs & $78(39)$ \\
Wells & $54(27)$ \\
Tanks & $28(14)$ \\
\hline
\end{tabular}

Table 2. Prevalence of geo-helminthic intestinal parasites among primary school pupils in Oyi, Anambra State.

\begin{tabular}{lllll}
\hline \multirow{2}{*}{$\begin{array}{l}\text { Number } \\
\text { Examined }\end{array}$} & $\begin{array}{l}\text { Number } \\
(\%)\end{array}$ & \multicolumn{3}{l}{$\begin{array}{l}\text { Number (\%) of Soil-transmitted } \\
\text { Helminths }\end{array}$} \\
\cline { 3 - 5 } & Ascaris & Trichuris & Ancylostoma \\
\hline 200 & $178(89)$ & $94(52.8)$ & $26(14.61)$ & $58(32.58)$ \\
\hline
\end{tabular}

Table 3. Distribution of Helminthic parasites among pupils in different locations in Oyi L.G.A, Anambra State.

\begin{tabular}{llllll}
\hline \multirow{2}{*}{$\begin{array}{l}\text { School } \\
\text { location }\end{array}$} & $\begin{array}{l}\text { No. of } \\
\text { pupils } \\
\text { examined }\end{array}$ & $\begin{array}{l}\text { No. of } \\
\text { pupils } \\
\text { infected }\end{array}$ & \multicolumn{3}{l}{$\begin{array}{l}\text { Number (\%) of Soil-transmitted } \\
\text { Helminthes }\end{array}$} \\
\cline { 5 - 6 } & Ascaris & Trichuris & Ancylostoma \\
\hline Nteje & 40 & $36(90)$ & $19(52.78)$ & $6(16.67)$ & $11(30.56)$ \\
Ogbunike & 40 & $33(82.5)$ & $14(42.42)$ & $8(20)$ & $11(33.33)$ \\
Nkwelle- & 40 & $37(92.5)$ & $21(56.76)$ & $4(10.81)$ & $12(32.43)$ \\
Ezunaka & & $36(90)$ & $22(61.11)$ & $5(13.89)$ & $9(25.00)$ \\
Awkuzu & 40 & $36(90)$ & $18(50.00)$ & $3(8.33)$ & $15(41.67)$ \\
Umunya & 40 & $178(89)$ & $94(52.80)$ & $26(14.61)$ & $58(32.58)$ \\
TOTAL & 200 & & & & \\
\hline
\end{tabular}

Ascaris showed the highest distribution in all the schools in different locations in Awkuzu while hookworm recorded highest in Umunya.

The prevalence of these respective parasites with respect to sex is shown in Figure1.

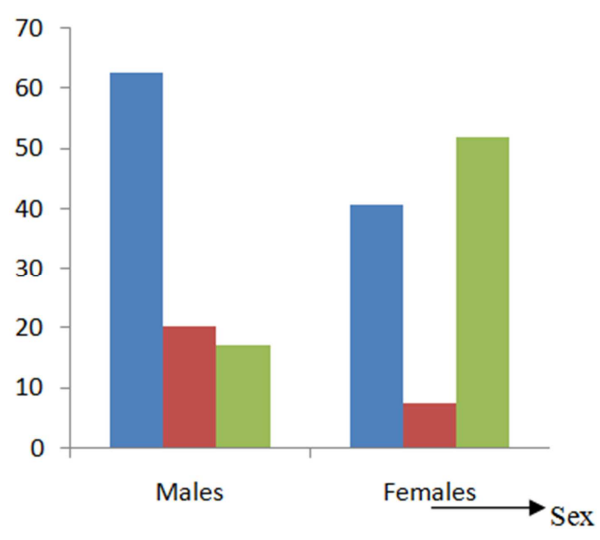

Key: Blue $=$ A. lumbricoides, Red $=$ T. trichuira, Green $=$ A. duodenale

Figure 1. Distribution of Intestinal Parasites according to sex among Geophagic pupils in Oyi, Anambra State.

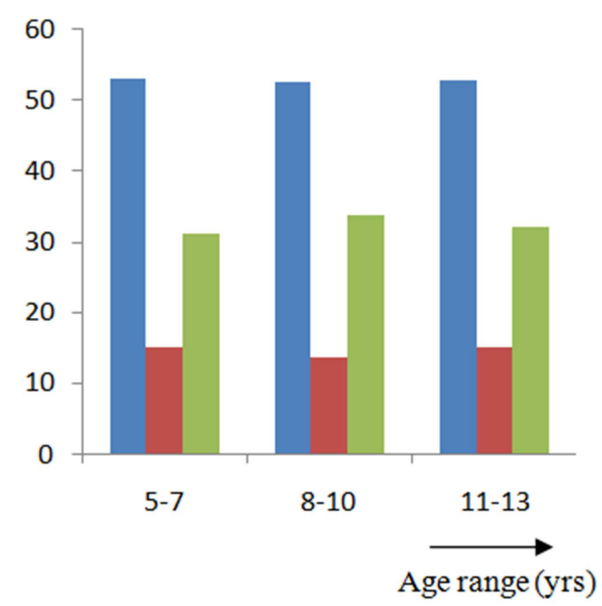

Key: Blue $=$ A. lumbricoides; Red $=$ T. trichuira Green $=$ A. duodenale

Figure 2. Distribution of intestinal parasites among geophagic primary school pupils with respect to age.

Among pupils between the ages of 5 and 7 years as shown in Figure 2, Ascaris showed the highest prevalence (53.03\%). A. duodenale was highest (52.54\%) among pupils in the agegroup of $8-10$ years. The distribution of these parasites was significantly dependent on the ages of the pupils $(\mathrm{p}>0.05)$.

Statistical Analysis to test Hypothesis: Generated data were subjected to Statistical Analysis using the "One way Analysis of Variance (ANOVA)" Method considering three hypotheses.

Nullhypothesis1: There is no relationship between geohelminthic infestation and geophagy among primary school pupils in Oyi L.G.A of Anambra State.

Table 4. Analysis of variance (ANOVA) for Table3 above.

\begin{tabular}{lllllll}
\hline $\begin{array}{l}\text { Source of } \\
\text { Variation }\end{array}$ & SS & df & MS & F & $\begin{array}{l}\text { P- } \\
\text { value }\end{array}$ & F crit. \\
\hline Between Groups & 0.007506667 & 4 & 0.001877 & 4.61306 & 0.9999 & 3.47805 \\
Within Groups & 4073.936867 & 10 & 407.3937 & & & \\
Total & 4073.944373 & 14 & & & & \\
\hline
\end{tabular}

The analysis above shows that $\mathrm{F}_{\text {crit. }}<\mathrm{F}_{\text {cat. }} ; \mathrm{P}>0.05$ (confidence level of $95 \%$ ) thus, we accept the null hypothesis. 
Null Hypothesis 2: The sex of geophagic pupils cannot be used as a factor to determine parasite infestation.

Table 5. ANOVA for Figure 1 above.

\begin{tabular}{lllllll}
\hline $\begin{array}{l}\text { Source of } \\
\text { Variation }\end{array}$ & SS & df & MS & F & P-value Fcrit \\
\hline $\begin{array}{l}\text { Between } \\
\text { Groups }\end{array}$ & 0.001066667 & 1 & 0.00106667 & 1.8117306 & 0.99899 & 7.708647 \\
$\begin{array}{l}\text { Within } \\
\text { Groups }\end{array}$ & 2355.030667 & 4 & 588.757667 & & \\
Total & 2355.031733 & 5 & & & \\
\hline
\end{tabular}

$\mathrm{F}_{\text {crit. }}>\mathrm{F}_{\text {cal }}$ and $\mathrm{P}$ value $>0.05$ (confidence level of 95\%) thus, we reject the null hypothesis.

Null Hypothesis 3: Age difference is not a significant factor in the distribution of parasites among geophagic pupils in Oyi L.G.A of Anambra State.

Table 6. ANOVA for Figure 2 above.

\begin{tabular}{|c|c|c|c|c|}
\hline $\begin{array}{l}\text { Source of } \\
\text { Variation } \\
\end{array}$ & SS & If MS & P-value & Fcrit \\
\hline $\begin{array}{l}\text { Between } \\
\text { Groups }\end{array}$ & 0.0910222222 & 0.045511111 & 0.0001242450 .9998758 & 5.14325285 \\
\hline $\begin{array}{l}\text { Within } \\
\text { Groups }\end{array}$ & 2197.8045336 & 366.3007556 & & \\
\hline Total & 2197.8955568 & & & \\
\hline
\end{tabular}

The analysis above shows that $\mathrm{F}_{\text {crit. }}>\mathrm{F}_{\text {cal }}$ and $\mathrm{P}$ value $>0.05$ (confidence level of $95 \%$ ) thus, we reject the null hypothesis.

\section{Discussion and Conclusion}

\subsection{Discussion}

Soil-transmitted helminthes (STHs) are great health problems in several tropical and sub-tropical countries. Infected school children are often physically and mentally compromised by STHs, leading to cognitive deficits, learning disabilities and high school absenteeism [3]. It also leads to high morbidity, mortality and economic loss to the country. This study has further reconfirmed the triad patterns of Ascaris, ancylostoma and trichuris infections common in rural communities in Nigeria andA frica as [15] established. This however is in contrast to findings made among school children in a study by the Centre for Disease Control [20]. By implication, the infestation of the identified helminthes among the primary school pupils, reveals that efforts by Federal, State and Local governments to eradicate worm infestation among children, have not been fully achieved.

The sex-related prevalence shows that females were more vunerable to ancylostoma infections, while males were more vunerable to Ascaris and trichuris infections. This conforms with the findings of [15]. Davies et al.[21] stated that geophagia is common among females which differed from the results obtained in the study which showed male pupils to be more geophagic than their female counterparts. The reason may be that boys are more playful than the girls. According to [16], geophagia is associated with school children in several African countries. Simelane [8] however, established that it cut accross people of allages. Children between the ages of 5 and 7 years were significantly more geophagic.

The prevalence of all species of STHs significantly varied with the highest prevalence in age group 5-7 years. This can be attributed to the frequent hand-to-mouth activity associated with children of that age range, and poor personal hygiene. Children become more active and adventurous with age which might expose them more to infections. They often eat indiscriminately, sometimes with unwashed hands. However, as they grow older, they become more conscious of personal hygiene. Studies have shown that there is positive and significant association between geophagy, age and geohelminthic infestation [11]. The children of farmers were observed to be infested more which probably may be attributed to their daily contact with soil, creating the link between geophagic practice among such children and their parent's occupational background.

Location did not seem to be a significant factor in geohelminthic infestation among pupils. However, global survey conducted by the WHO declared that children who live in rural areas are exposed to soil-transmitted parasites and in great numbers of over 600 million cases annually across the globe [5]. Again, Geissler and Wenzel [22] revealed that most geophagic practices are prevalent in rural areas. They however stated that in some urbanized areas such as Johnnesburg, CapeTown, and Harare in Southern Africa, there is high level of geophagic practice among the populace.

Peer-group influence has been said to be a major reason why children ever consume geophagic materials such as calabash chalks, which can even lead them to addiction [15]. This was corroborated in the current study as $75 \%$ of geophagic pupils were introduced to the practice by their peers.

Ecological factors such as climate and temperature play major roles in the distribution and prevalence of these parasites, with Africa being the most vunerable continent [8]. Periodic de-worming may not have been effectively carried out among school children in Oyi, which might have led to the high prevalence rates recorded. This may be connected to possible low socio-economic and educational background of parents as well as local authorities.

\subsection{Conclusion}

Findings from this study reveal that there are three orally acquired geo-helminthes that are common among geophagic primary school pupils in Oyi Local Government Area, Anambra State. The result of this study adds to the store of baseline data on the occurrence of helminthes infections among Nigerian pupils. Improved sanitation by provision of modern toilet facilities, health education through enlightenment campaigns (on the dangers of soil consumption and contact), school-based health programmes such as hand washing, and regular/early de-worming of pupils, will go a long way in reducing infection. Prospective studies to access the impact of intestinal helminthes in school children as regards their school performance (intelligence and absenteeism), and growth is advocated. 


\section{References}

[1] E. Landa and C. Feller, Soil and Culture. Springer Publishers, Netherlands, 2009, P. 370.

[2] R. Krishnamani and W. Mahaney, "Geophagy among primates: Adaptive significance and ecological consequences," Animal Behavior. 59(5): 899 - 915, 2000.

[3] G. Callahan, "Eating Dirt," Emerging infectious diseases, 9(8): 1016 - 1021, 2003.

[4] D. Jackson, Cleanse and purify thyself, Book1. Christboe Publishing, Oregon. 2007, P. 25.

[5] World Health Organization, "Soil-transmitted Helimnth infections," www.who.int/mediacentre/factsheets/fs366/en, 2014. Accessed 10/01/2015.

[6] M. Mills, "Nursing for Women's Health," Association of Women's health, Obstetrics and Neo-natal nurses (AWHONN) Journal. 11(3): 266 - 267, 2007.

[7] L. Crawford and K. Bodkin, "Health and Social impacts of Geophagy," McGill School of Environment Journal, 6(1):15 20, 2011.

[8] N.O. Simelane, "The socio-cultural aspects of geophagia in southern Africa," A paper presented at the Int'l conference and enzootic geophagia in South Africa, 19 - 24 Oct., 2008.

[9] R. Kusher, B. Gleason and V. Shanta-Retelny, "Re-emergence of Pica following gastric bypass surgery for Obesity: A new presentation of an old problem," Journal of American Dietetics Association, 104(9):1393 -1397, 2004.

[10] S. Carmichael, G. Shaw, D. Schaffer, C. Laurent and S. Selvin, "Dieting behaviors and Risk of neural tube defects," American Journal of Epidemiology. 158:1127-1131, 2003.

[11] P. Hooda, C. Henry, T. Seyoum, M. Armstrong and M. Fowler, "The potential impact of geophagy and the bio-availabilty of iron in human nutrition," Enviromental Geochemistry and Health. 24(4): 305 - 319, 2002.

[12] S. Young, M. Wilson, D. Miller and S. Hiller, "Toward a comprehensive approach to the collection and analysis of pica substances with emphasis on geophagic materials," Public Library of Science Journal (PLOS) one, 3(9): 3, 2008

[13] J. Hunter and R. DeKleine, "Geophagy in Central America," American Geographical Society, 74(2): 157 - 169, 1984.

[14] L. Lopez, C. Soler and M. de Portela, "Pica during pregnancy; a frequently under estimated problem," Archivos Latino americanos de Nutricion 54(1): 17 - 24, 2004.

[15] P. Omah, A. Ibidapo and O. Okwa, "Prevalence and Risk Factors of Geo-helminthiasis in Umuebu Community, Ukwuani L.G.A Delta State, Nigeria," British Journal of Medicine and Medical Research. 4(5): 1175 - 1186, 2013.

[16] S. Anyangwe, "The epidemiology of geophagia in humans," A paper presented at the Int'l conference and enzootic geophagia in South Africa, $19-24$ Oct., 2008.

[17] M. Elom, M. Alo, U. Ugah, I. Uchenna and A. Gweon, "Intestinal helminthes associated with geophagy in pregnancy in Afikpo North, Ebonyi State," World Journal of Medicine and Medical Research. 1(50): 92 - 97, 2013.

[18] B. Emmanuelle and A. Solorzano, "Public science and politics in the Rockefeller Foundation's Hookworm campaign in Mexico," Social Science and Medicine. 49(9): 1197 - 1213, 1999.

[19] M. Cheesbrough, District Laboratory Practice in Tropical Countries. Part1. Cambridge University Press, United Kingdom, 1998, p193 - 199.

[20] Centre for Disease Control, "Soil-transmitted Helminthes," www.cdc.gov/parasites/sth, 2013, Accessed 13 ${ }^{\text {th }}$ July, 2014.

[21] T.C. Davies, A.O. Solomon, P. Lar and P.W. Abraham, "A socio-economic study of geophagy in Jos, Plataeu Nigera," A paper presented at the Int'l conference and enzootic geophagia in South Africa, 19 - 24 Oct., 2008.

[22] P. Geissler and R. Wenzel, "The significance of earth eating: Social and Cultural Aspects of Geophagy among Africans," Journal of the International African Institute, 70(4): 653 - 682, 2000 . 